\title{
Social Media Usage and Its Impact on Academic Performance on Tertiary Education Students in the Bono Region of Ghana
}

\author{
Ernest Apraku \\ Berekum College of Education \\ Department of Social Sciences \\ Hans Kwaku Duah \\ Berekum College of Education \\ Department of Social Sciences \\ John Kwaku Bofa \\ Department of Community Development \\ Sunyani West District Assembly
}

\begin{abstract}
This study examined the impact of social media usage on academic performance among students in Colleges of Education. Quantitative method and descriptive survey design were used in this study. Simple random sampling technique was adopted to select 200 students to participate in the study. Questionnaires were used to elicit data from respondents. Data collected were analyzed using SPSS. The following were major findings: the study revealed that the majority of students used WhatsApp and Facebook for making friends and chatting. Majority of the students indicated that social media sites affected their academic performance negatively because they were distracted from their studies. Also, students shared ideas, discussed and shared examination questions among themselves on social media sites. The researcher recommends creation of awareness on applications that are academic oriented so that the students can utilize them whenever they are online such as google drive, drop box, iBook among others.
\end{abstract}

Keywords: Social Media, Usage, Impact, Academic Performance, Students

\section{Introduction}

Social media has exploded as a category of online discourse where people create content, share it, bookmark it and network at a prodigious rate. Because of its ease of use, speed and reach, social media is fast changing the public discourse in society and setting trends and agenda in topics that range from the environment and politics to technology and the entertainment industry (Asur \& Huberman, 2010). Through this platform, individuals and organizations create profiles, share and exchange information on various activities and interests. An interesting aspect of social media is that, it is not limited to desktop or laptop computers but could be accessed through mobile applications and smart phones making it very accessible and easy to use. In the past years, social media websites have become common; giving young people a new way to interact with each other and communicate with the world. Social networking became popular between 2004 and 2006, after Facebook and Myspace were created. Facebook, for example, has over 500 million members and it is still growing and approximately $85 \%$ of undergraduate students are Facebook users (Schneider, 2010). Social networking websites provide tools by which people can communicate, share information, and create new relationships. With the popularity of social networking websites on the rise, our social interaction is affected in multiple ways as we adapt to our increasingly technological world. The way web users interact and talk to each other has changed and continues to change. Communicating through the internet and social networking websites is quite different from communicating in person-to- person situation. When users communicate through these websites, they use things like instant message (IM) and chatting as well as status or Twitter updates to talk to friends and express themselves (Kaitlin, 2010).

\subsection{Statement of problem}

There have been a lot of debate on various platforms and media as to the impact that social media has on society and specifically, on users' education. Some of these studies found a drop in students' grades and academic performance, and lack of time for studies as consequences of social media network participation (Banquil, Chuna, Leano, Rivero, Bruce \& Dianalan, 2009; Karpinski \& Duberstein, 2009; Ndaku, 2013). 
The rapid advancement of media technology has had a great impact on the way people communicate on a daily basis. The growing dimension of the use of social media among the youth of today cannot be overemphasized.

Over the years, social networking among students has become more and more popular. It is a way to make connections, not only on campus but with friends outside of school. Social networking is a way that helps people feel they belong to a community. Due to the increased popularity of it, economists and professors are questioning whether grades of students will not be affected by how much time is spent on these sites. Preliminary investigation and interviews with some teachers and students revealed a number of challenges in relation to student's participation on social media networks. These included a high addiction rate among students which affects their time of study, the wrong usage of grammar and spelling in social media discourse as well as distracting students from their studies (Ahmed \& Qazi, 2011). As stated by Ndaku (2013), students spend a lot of time on social networking sites than in their academic activities and this affects their academic performance.

MehMood and Taswir (2013), Jacobsen and Forste (2011) believe that the use of technology such as internet is one of the most important factors that can positively or adversely influence educational performance of students. Many parents and guardians are worried that students are spending too much time on Facebook and other social media sites and have not enough time to study. Though parents are worried about students' constant use of the social media sites, many students continue to utilize these sites on a daily basis.

A number of studies in relation to social media have been conducted in Ghana. These, however have centered on social media use in basic schools (Amofah-Serwah \& Dadzie, 2015) and social media usage in second cycle level (Apeanti \& Danso, 2014). Since these studies have been conducted in basic schools and second cycle levels the researcher finds it necessary to conduct this study on the impact of social media participation on academic performance of students in tertiary education institutions. Some of the studies, Lenhart, Smith and Zichur (2010), Boyd (2010), Enriquez (2010), Karpinski and Duberstein (2009), Khan (2009), Asur and Huberman (2010), conducted on students' use of the social media sites and its impact on academic performance focused on students in the developed world. It is against this background that it became necessary to conduct this research which aimed at investigating students' use of social media sites and their impact on academic performance among tertiary education students in Ghana.

\subsection{Objectives}

The general objective of the study is to find out the impact of social media usage on academic performance among tertiary education students. The specific objectives are; to identify the purpose of using the social media by students and to find out the effects of social media participation on the students' academic performance.

\subsection{Research questions}

This research paper seeks to answer the following questions. What are the purpose of using the social media by the students? What are the effects of social media participation on student's academic performance?

\subsection{Significance of the study}

The significance of this study are as follows. The study will help researchers with more information on the Influence of social media on the student's academic performance. It is expected that the output of this research will benefit students and the administration of tertiary institutions as will show the level of the students' use of social media sites. This shall help them to understand how best to sustain the students attention on using social networking sites. Also this work will be of immense benefit to the field of Library and information sciences as it will be in addition to existing literature. And the study will add to the available academic literature on social media. It will provide relevant material for students and other researchers undertaking similar research.

\subsection{Delimitation of the Study}

This study was delimited to students of Berekum and St. Ambrose Colleges of education in the Bono Region. It focused on the effects of social media participation on the students' academic performance.

\section{Literature Review}

\subsection{Theoretical review}

Uses and gratification theory is a theory that seeks to appreciate the reasons behind individuals' choice of media. A study was conducted on the application of the Use and Gratification Theory to the mobile phone usage. The conclusion was that fashion, entertainment, easy accessibility and status could not be over emphasized when it comes to the usage and gratification of mobile phones, (Ho \& Syu, 2010). Again, this theory assumes that audience who are active can be caught in the web of addiction with respect to their favorite media activity. It is upon this assumption that learning habits and for that matter education could be influenced by the social media participation by students. 


\subsection{The Concept of Social Media}

Lusk (2010) defined social media as an aspect of the Internet which allows individuals and groups to create and publish online content, share content, and interact about it through the use of Facebook, Skype, Blogs, Myspace, LinkedIn, Yahoo Messenger, WhatsApp and Twitter.

The study simplifies social media as a platform on the internet where young and old generations meet to communicate, share ideas and develop friendship by use of Facebook, Skype, Blogs, Myspace, LinkedIn, Yahoo Messenger, WhatsApp and Twitter. Social media is that means that employs mobile and web based technology to create highly interactive platforms via which individuals and communities share, co-create, discuss and modify users' generated content (Kietzmannn, Hermkens, McCarthy \& Silvestre, 2012).

\subsection{Academic Performance}

Academic performance is the dependent variable of our research and is defined as the performance a student has maintained in his/her academic career. Academic performance at university level is considered up to the mark if the student has persistently maintained his GPA. However, different factors may have an effect on student's academic performance, such as social media usage. In light of this, our objective is to investigate the effect of social media on academic performance of students and to determine whether it has a negative or positive relationship.

\subsection{The effects of Social Media Usage on Academic Performance of Students}

Over the years, many studies have been conducted and social media has depicted both positive and negative effect on the academic performance of the students. There are certain factors that influence the relationship between social media and academic performance such as how long students use social networking sites? What time of the day do they use these sites the most? A handful of studies have discussed the relationship between these variables internationally as well as in Pakistan. A research was done by Madge, Meek and Wellens (2009), based on the universities in the U.K. The study showed negative relationship between Facebook and the academic performance of students. However, the study did not focus on which students were using Facebook and what time of the day they used it the most. Moreover, the sample used for the study was homogenous thereby restricting their research findings. Furthermore, Paul, Baker and Cochran (2012) suggested that a negative relationship exists between time spent by students on social networking sites and their academic performance. A research by Asdaque, Khan and Rizvi (2010) was conducted on 100 undergraduate students of two federal universities in Pakistan. The research focused on the use of internet and its effects on academic performance. The results suggested a negative relationship. According to Akhtar (2013), excessive usage of internet can become an addiction especially among students and it can cause academic problems. The author suggested that internet addiction can cause a fall in time spent on studies, major drop in grades, low interest in extracurricular activities and lack of interest in classes. Jocabsen and Forste (2011) found a negative relationship between the use of various media, including mobile phones, and self-reported GPA among first year university students in the United States. Conversely, according to Pasek, More and Hargittai (2009), the use of Facebook has a positive relationship with academic performance. According to their research, the students with higher grades tend to spend more of their time on Facebook. Yunus, Nordin, Salehi, Embiand Salehi (2012) indicate that students gained more vocabulary and improve their writing skills as a result of their participation on social networks such as Facebook and Twitter. Again, other studies like Ahmed and Qazi (2011), Hanqittai and Hsich (2010), Pasek and Hanqittai (2009), conducted on the same topic exposed no correlation between social media and students' academic performance. Negussie and Ketema (2014) study in Ethiopia also indicated that there is no significant relationship between times spent on social networks such as Facebook with students' grade point average (GPA). In conclusion, the above studies reviewed have revealed that there are benefits and risks associated with using social media, and have reported its effect on students' academic performance.

\section{Methodology}

\subsection{Introduction}

This section presents the methodology that was used in carrying out the research study. It covers research design, target population, sample and sampling techniques, research instruments, data collection procedure and finally method to be used for data analysis and ethical consideration.

\subsection{Institutional Setting}

Berekum College of Education (BECOLED) is a teacher training college located in the Bono Region of Ghana. The college was established in February, 1953 as a Government institution. Student enrolment as at September 2017 was 1240, comprising of 744 men and 496 women. St. Ambrose College of Education is also a teacher training college located in the Bono Region. It was inaugurated on January 21, 2011. Student enrolment as at September 2017 was 480 , comprising of 350 men and 130 women. 


\subsection{Research Type and Design}

This study was quantitative research and employed descriptive survey research design. The study collected information about people, their attitudes and opinions, hence the need to use the descriptive survey research design.

\subsection{Population}

The research population for this study was drawn from Colleges of Teacher Education in Bono Region of Ghana. The target population of this study was students in Berekum and St. Ambrose Colleges of Education.

\subsection{Sample and Sampling Techniques}

Researchers have not concerted on any particular number of the sample size in educational research (Kuranchie, 2014). The sample size for this study was 200 respondents. Probability simple random sampling technique was adopted to select the respondents. This was employed in order to give every respondent an equal chance of being part of the study. 140 students from Berekum College of education and 60 students from St. Ambrose College of Education.

\subsection{Research Instrument}

Questionnaires were used in the collection of data from the respondents. The research instrument was ordered into two sections (A and B). Section "A" comprised background information items on respondents. Section "B" was constructed based on the objectives of the study. Questionnaire was used because; it allowed respondents to take time to think about questions before responding to them, it is convenient for gathering data from a large sample size and the respondents express their views without the possibility of influence by the researcher.

\subsection{Data Collection Procedure}

The questionnaires were personally administered to respondents by the researcher. The researcher thoroughly explained the details of the questionnaire to the respondents thoroughly in order to prevent respondents skipping, avoiding or giving wrong information to certain pertinent questions. The purpose was to help the respondents to understand the content of the questionnaire and to do away with ambiguities, suspicions, partiality and also be able to provide independent opinions and views. The researcher established a good rapport with respondents throughout the distribution and collection periods to enable them feel comfortable to give independent and accurate information. All questions were collected the same day.

\subsection{Data Analysis Techniques}

Data obtained from the field was edited systematically to ensure that every questionnaire is rightly completed. Data were then be numbered and coded using a coding manual as a guide. The Statistical Package for the Social Sciences (SPSS) version 17.0 was used to analyze the data. Results of the study were presented using frequency distributions and percentages.

\subsection{Ethical consideration}

At the start of the data collection process, the rationale of the study was explained to the respondents to assure them of anonymity and confidentiality in order to clear their minds about any uncertainties, suspicions and fear. This enabled them to participate in the research with free minds.

\section{Results and Discussion}

\subsection{Presentation of Results and Discussion}

Table A presents the gender of distribution of the respondents, and out of the 200 students used, 108 representing 54\% were males while the remaining 92 representing $46 \%$ were females. On the age distribution of respondents, it was found in table B that $46 \%$ of the respondents were 24years and above. This was followed by $32 \%$ of respondents having their ages between 18-20 years and 22\% were between 21-23 years. From table C, 192 respondents (96\%) were members of an online social media sites, and 8 respondents $(4 \%)$ were not members of an online social media site. From Table D respondents gave the following as social media sites they patronize. The results show that $66 \%$ of the students patronized Facebook, WhatsApp 30\%, and Yahoo Messenger and Instagram having 2\% respectively. The analysis shows that Facebook is the most social media site students patronize. This confirms Schneider's (2010) assertion that approximately $85 \%$ of undergraduate students are Facebook users. Table E presents results on how participation on social media sites affects the academic performance of students. For the sake of discussion, strongly agree and agree combined to become agree, disagree and strongly disagree become disagree and not sure remains the same. From Table E below, 52\% of the students agreed with the statement: comparing my grades before and after participating on social media sites, I experienced drop in my academic performance, $34 \%$ disagreed with that while 
$14 \%$ remain neutral. This meant that majority of respondents indicated that their grades dropped when they began participating on social media sites. This study confirms MehMood and Taswir's (2013) study that the use of technology such as the internet is one of the factors that can influence students' performance positively or adversely. Furthermore, the use of social media during vacation was agreed by $64 \%$ of the students which also meant that the majority of the students spend most of their time during vacation participating on social media sites rather than reading their books. In addition, $64 \%$ of the students agreed that social media sites affected their academic performance negatively because they were distracted from their studies. This also meant that most respondents affirmed that social media distracted them from their studies thereby affecting their academic performance negatively.

According Kuppuswamy \& Narayan (2010), social media sites such as, Facebook, Myspace and Yahoo messenger are popular and have become part of daily life for an increasing number of people. The study argues that these social media sites distract students from their studies. He concluded that social media sites have both positive as well as negative impact on the education of youth, depending on one's interest of use.

Again, 58\% of the students indicated that they found it hard concentrating on their studies when they knew they could play games and chat just by logging in. This meant that majority of the students found it hard concentrating on their studies because they chatted when they had the least opportunity to participate on social media sites. Furthermore, $48 \%$ of the students disagreed with statement that social media use has affected my spelling when writing examination while $42 \%$ of the students attested to the fact that their spelling of words have been negatively affected as a result of using short cut words when chatting with their friends on social media sites. Half $(50 \%)$ of the students also felt addicted to social media which they indicated affected their academic life negatively. Majority (52\%) of the students indicated that their grades would improve if they stopped participating on social media sites while $32 \%$ of them did not support the statement. The idea was that most of the respondents were aware that social media use negatively affects their academic performance. This was because it was confirmed in the study that most of the respondents use the social media sites for other purposes rather than academic work. The implication is that the use of social media may likely not bring any improvement in the academic work of respondents. Majority of students (76\%) agreed with the statement; I do discussions of examination with my friends on social media site. This implied that majority of the students used social media sites for discussion on examinations. Additionally, $72 \%$ of the students disagreed with the statement that social media sites are personal/social and cannot be used for educational purposes. This implies that social media sites could be used for educational purposes as indicated by majority of the students. Lastly, $58 \%$ and $82 \%$ of the students indicated that social media has improved their reading skills and their English language usage had been affected positively respectively. As stated by Yunus et al. (2012), students gained more vocabulary and improve their writing skills as a result of their participation on social networks and this in turn improved on their reading skills.

Table F presents the types of information students share with their friends on social media sites. The researcher allowed multiple responses to the question because respondents could find themselves in one or two of the situations. Out of the total valid responses, $156(69 \%)$ of the students indicated that they used social media sites for social interaction. Socialization according to the research entailed making new friends and keeping in touch with fellow students, family and teachers. Most student were found to spend more time chatting, sharing pictures, tweeting and re-tweeting thus the high number of those engaged in socializing. The high numbers were also attributed to the many groups formed on platforms like WhatsApp where the students engage in endless conversations. Also, 22\% of the students indicated that they used social media sites for searching jobs. Current affairs had the least response with $9 \%$ which implies that very few students if any seek information of this subject matter on social media sites. In this research current affairs meant news and information that was trending and making headlines at the particular moment. The lower response on current affairs could be attributed the lack of interest in matters relating to politics, governance, conflict resolution and environmental issues that are less interesting to the students. Table $\mathrm{G}$ dealt with the purpose for which respondents used social media networks. The researcher allowed multiple responses to the question because respondents could find themselves in one or two of the situations. Out of the total valid responses, $60(20 \%)$ respondents indicated that they used social media sites for discussions with friends on school matters. In addition, $138(47 \%)$ respondents claimed that they used social media networks for chatting while 80 (27\%) indicated that they used social media sites for making friends. Chatting was therefore identified as the main purpose for which students used social media sites.

\section{Summary, Conclusion and Recommendations}

\subsection{Summary of findings}

This study examined the impact of social media on academic performance among students in Berekum and St. Ambrose Colleges of Education. Quantitative and descriptive survey designs were used in this study. Probability simple random sampling technique was adopted to select 200 students. Questionnaires were used to elicit data from respondents. The following were major findings: 
1. Majority of the students were members of an online social media sites with majority using Facebook.

2. Majority of the students indicated that social media sites affected their academic performance negatively because they were distracted from their studies.

3. Majority of the students found it hard to concentrate on their studies because they chatted when they had the least opportunity to participate on social media sites.

4. Majority of respondents indicated that their grades dropped when they began participating on social media sites.

5. Half of the students also felt addicted to social media which they indicated affected their academic life negatively.

6. Majority of the students disagreed with the statement that social media sites are personal/social and cannot be used for educational purposes. This implies that social media sites could be used for educational purposes as indicated by the majority of the students. Majority of the students used social media sites for discussion on examinations.

7. On the kind of information students seek on online social media sites, the study found out that majority of the students used social media sites for social interaction.

\subsection{Conclusions}

The study has revealed that despite the benefits that come with the participation of students on social media sites, it could impact negatively on their academic performance if not used properly. A lot of benefits abound in the use of social media sites such as sharing information and ideas, discussion on issues and others. Despite the benefits that come with the participation of students on social media sites, its misuse could affect the academic life of the student and thereby their performance. Social media sites affected students' academic performance negatively because they were distracted from their studies.

\subsection{Recommendations}

1. The researcher recommends creation of awareness on applications that are academic oriented so that the students can utilize them whenever they are online such as google drive, drop box, iBook among others.

2. Teachers should be encouraged to interact with the students on social media sites, for instance having a group on WhatsApp platform where they exchange views about a particular subject even when they are on holidays. This will in turn encourage the use of social media sites to improve students' academic performance.

\subsection{Suggestions for Further Study}

1. The researcher recommends for an in-depth study and critically looking at the performance variance of a particular student over time when he/she was using and when he/she was not using social media sites.

2. A study could be done on the impact of social media sites on academic performance of students in the Nursing Training College and compare the findings with those in the College of Education.

Table A: Gender Distribution of Respondents

\begin{tabular}{lcc}
\hline Gender & Frequency & Percentage \\
\hline Male & 108 & 54 \\
Female & 92 & 46 \\
\hline Total & $\mathbf{2 0 0}$ & $\mathbf{1 0 0}$
\end{tabular}

Source: Field survey, 2017

Table B: Age Distribution of Respondents

\begin{tabular}{lcc}
\hline Age (years) & Frequency & Percentage \\
\hline $18-20$ & 64 & 32 \\
$21-23$ & 44 & 22 \\
24 years and above & 92 & 46 \\
\hline Total & $\mathbf{2 0 0}$ & $\mathbf{1 0 0}$ \\
\hline
\end{tabular}

Source: Field survey, 2017

Table C: Are you a member of an online social media sites

\begin{tabular}{lcc}
\hline Response & Frequency & Percentage \\
\hline YES & 192 & 96 \\
NO & 8 & 4 \\
\hline Total & $\mathbf{2 0 0}$ & $\mathbf{1 0 0}$ \\
\hline
\end{tabular}

Source: Field survey, 2017 
Table D: Social media sites students Patronize

\begin{tabular}{lcc}
\hline Response & Frequency & Percentage \\
\hline Facebook & 132 & 66 \\
Instagram & 4 & 2 \\
WhatsApp & 60 & 30 \\
Yahoo Messenger & 4 & 2 \\
\hline Total & $\mathbf{2 0 0}$ & $\mathbf{1 0 0}$ \\
\hline
\end{tabular}

Source: Field survey, 2017

Table E: Effect of social media participation on academic performance $(\mathrm{N}=200)$

\begin{tabular}{|c|c|c|c|c|c|}
\hline Statement & SA & $\mathbf{A}$ & NS & $\mathbf{D}$ & SD \\
\hline $\begin{array}{l}\text { Comparing my grades before and after participating on } \\
\text { SMS and I experienced drop in my academic performance }\end{array}$ & 14 & 38 & 14 & 18 & 16 \\
\hline $\begin{array}{l}\text { During vacation I spend a lot of time participating in social } \\
\text { media than reading my books }\end{array}$ & 28 & 36 & 6 & 24 & 6 \\
\hline $\begin{array}{l}\text { These SMSs influence my academic performance negatively, } \\
\text { because they distract me from my studies }\end{array}$ & 36 & 30 & 10 & 16 & 8 \\
\hline $\begin{array}{l}\text { Finding it hard concentrating on my study knowing that I can } \\
\text { play online games and visit these sites just by logging into them }\end{array}$ & 18 & 40 & 22 & 10 & 10 \\
\hline Social media use has affected my spelling when writing exams & 18 & 24 & 10 & 36 & 12 \\
\hline $\begin{array}{l}\text { Addiction to social media is a problematic issue that } \\
\text { affects my academic life }\end{array}$ & 12 & 38 & 8 & 22 & 20 \\
\hline My grades will improve if I stop participating on SMS & 16 & 36 & 16 & 22 & 12 \\
\hline I do discussions of examination with my friends on SMS & 34 & 42 & 4 & 14 & 6 \\
\hline $\begin{array}{l}\text { SMS are personal/social and cannot be used for educational } \\
\text { purposes }\end{array}$ & - & 16 & 12 & 16 & 56 \\
\hline Social media has improved my reading skills & 20 & 62 & 8 & 8 & 2 \\
\hline Social media affects my English Language usage positively & 14 & 44 & 10 & 16 & 16 \\
\hline
\end{tabular}

Source: Field survey, 2017

KEY: $\mathrm{SA}=$ strongly agree, $\mathrm{A}=$ agree, $\mathrm{NS}=$ not sure, $\mathrm{D}=$ disagree, $\mathrm{SD}=$ strongly disagree, $\mathrm{SMS}=$ Social Media Sites

Table F: Type of information students share with their friends on SMS

\begin{tabular}{lcc}
\hline Variable & Frequency & Percentage \\
\hline Social interaction & 156 & 69 \\
Current affairs & 20 & 9 \\
Jobs & 50 & 22 \\
\hline Total & $\mathbf{2 2 6}$ & $\mathbf{1 0 0}$ \\
\hline
\end{tabular}

Source: Field survey, 2017

Table G: Purpose for using Social Media Sites

\begin{tabular}{lcc}
\hline Variable & Frequency & Percentage \\
\hline Discussion & 60 & 20 \\
Chatting & 138 & 47 \\
Download music and video & 11 & 4 \\
Posting photos & 7 & 2 \\
Making friends & 80 & 27 \\
\hline Total & $\mathbf{2 9 6}$ & $\mathbf{1 0 0}$ \\
\hline
\end{tabular}

Source: Field survey, 2017 


\section{References}

Ahmed, H. \& Qazi, W. (2011). A look out for academic impacts of social networking sites (SNSs): A student based perspective. African Journal of Business Management, 5(12), 5022-5031.

Akhtar, N. (2013). Relationship between internet addiction and academic performance among University undergraduates. Educational Research and Reviews, 8(19), 1793-1796.

Amofa-Serwaa D. and Dadzie, K. (2015). The Impact of WhatsApp and Facebook Usage on Students Performance in Tertiary Institutions in Ghana. Journal of Education and Practice, 5(6), 157- 165.

Apeanti, W. O. and Danso, E. D. (2014). Students' Use of Social Media in Higher Education in Ghana. Innovative Journal, 3(1), 3-9.

Asdaque, M. M., Khan, M. N. and Rizvi, S. A. A. (2010). Effect of internet on the academic performance and social life of university students in Pakistan. Journal of Education and Sociology. 4(2), 23-26.

Asur, S. \&. Huberman, B.A. (2010).Predicting the Future with Social Media. Social Computing Lab: HP Labs, California: Palo Alto.

Banquil, K., Chuna, N. A., Leano, G. A., Rivero, M. A., Bruce, C. A., Dianalan, S. N., Matienzo, A. R., \& Timog, N. U. (2009). Social networking sites affect one's academic performance adversely. [Online] Available: http://www.ust.edu.ph (December 12, 2016).

Boyd, D. (2010). Taken Out of Context: American Teen Sociality in Networked Publics Berkeley, [Online] Available:www.danah.org/papers/TakenOutOfContext.pdf (January 16, 2017).

Davis, C. H. F., Canche, M. S. G., Deil-Amen, R. and Rios-Aguilar, C. (2012). Social Media in Higher Education: A Literature Review and Research Directions. Arizona: The Center for the Study of Higher Education at the University of Arizona and Claremont Graduate University.

Englander, F., Terregrosa, R. \& Wang, Z. (2010). .Internet use among College Student: Tool or Toy? Educational Review. 62(1), 85-96.

Hargittai, E. \& Hsieh, Y. P. (2010). Predictors and Consequences of Differentiated Practices on Social Network Sites. Information, Communication \& Society, 13(4), 515-536.

Ho, H. \& Syu, L. (2010). Uses and gratifications of mobile application users. [Online] Available http://ieeexplore.ieee.org/stamp/stamp.jsp?tp=\&arnumber=5559869 (April 20, 2017).

Jacobsen, W. C., \&Forste, R. (2011). The Wired Generation: Academic and Social Outcomes of Electronic Media Use Among University Students. Cyber Psychology Behaviour \& Social Networking 18(5), 275-285.

Kaitlin, C. (2010) Social Media Changing Social Interactions. Student Journal of Media Literacy Education, Issue 1, 1. $1-11$.

Karpinski, A, C. \& Duberstein, A. (2009). A Description of Facebook Use and Academic Performance among Undergraduate and Graduate Students. San Diego, California: American National Research Association. 1119.

Kaplan, A. M. \& Haenlein, M. (2010). Users of the world, unite, the challenges and opportunities of social media. Business Horizons, 53(1), 59-68.

Karpinski, A. (2009). A description of Facebook use and academic performance among undergraduate and graduate students. Annual Meeting of the American Educational Research Association, San Diego, Calif.

Khan, U. (2009). Facebook students underachieve in exams. Daily Telegraph. [Online] Available: http://www.telegraph.co.uk/education/educationnews (October 12, 2016).

Kietzmann, J.H., Hermkens, K., McCarthy, I.P., \&Silvestre, B. S. (2012). Social media? Get serious understanding the functional building blocks of social media. Business Horizons, 54(3), 241-251.

Kuranchie, A. (2014). Research Made Easy. Kumasi: Bookworm Publications.

Kuppuswamy, S., \& Narayan, P. (2010). The Impact of Social Networking Websites on the Education of Youth. International Journal of Virtual Communities and Social Networking (IJVCSN), 2(1), 67-79.

Lenhart, A., Purcell, K. Smith, A. \&Zichur, K. (2010). Social Media \& Mobile Internet Use among Teens \& Young Adults a report for the Pew Internet \& American Life Project, Washington.

Lusk, B. (2010). Digital Natives and Social Media Behaviors: An Overview. The Prevention Research, 17, 3-6.

Madge, C., Meek, J. and Wellens, J. (2009). Facebook, Social integration and informal learning at University: 'It is more for socializing and talking to friends about work than for actually doing work'. Learning, Media and Technology, 34(2), 141-155.

MehMood, S, \&Taswir, T, (2013). The effect of social networking site on the Academic Performance on students in college of applied sciences, Nizwa, Oman. International Journal of Arts and Commence.2 (1), 111-123. 
Ndaku, A. J. (2013). Impact of Social Media on the Students' Academic Performance: International Journal of Arts and Commerce, 2(1), 111-115.

Negussie, N. \& Ketema, G. (2014). Relationship between Facebook Practice \& Academic Performance of University Students. Asian Journal of Humanities and Social Sciences, 2(2), 1-7.

Pasek, A. \& Hargittai, R. (2009). Facebook and academic performance: Reconciling a media sensation activities with data. 14(5), 5-4.

Pasek, J., More, E. and Eszter H. (2009). Facebook and academic performance: Reconciling a media sensation with data. First Monday, 14(5), 29-32.

Paul, J. A., Baker, H. M. and Cochran, J. D. (2012). Effect of online social networking on student academic performance. Computers in Human Behaviour, 28(6), 2117-2127.

Rouis, S., Limayem, Q. \& Salehi-Sangari, R. (2011). Impact of Facebook Usage on Students' Academic Achievement: Role of Self-Regulation and Trust. Journal of Research in Educational Psychology, 9(3), 961-994.

Schneider, N. (2010). Facebook, Other Social Network Sites Could Lead to Lower Grades for Students. [Online] Available:www.associatedcontent.com/article (March, 15, 2017).

Wang, F., Chen, J. \& Liang, A. (2011). The Effects of Social Media on College Students. The Alan Shawn Feinstein Graduate School. Providence: Johnson \& Wales University.

Yunus, M., Nordin, N., Salehi, H., Embi, M. A. and Salehi, Z. (2012). The Use of Information and Communication Technology in Teaching ESL Writing Skills. English Language Teaching, 6(7), 1-8. 